\title{
Severe exacerbations predict excess lung function decline in asthma
}

\author{
T.R. Bai*, J.M. Vonk ${ }^{\#}$, D.S. Postma and H.M. Boezen\#
}

ABSTRACT: Severe asthma exacerbations are periods of intense airway inflammation that have been hypothesised to contribute to structural changes in the airways. If so, accelerated lung function decline over time should be more prevalent in adult patients with asthma who have frequent exacerbations than those without, but to date this has not been demonstrated.

A cohort study was performed in order to investigate the effect of severe exacerbations on the progression of airway obstruction in 93 nonsmoking asthmatics with moderate-to-severe disease prior to treatment with inhaled corticosteroids. Subjects were followed for $\geqslant 5$ yrs (median followup 11 yrs).

In total, $56(60.2 \%)$ subjects experienced at least one severe exacerbation (median rate $\left.0.10 \cdot \mathrm{yr}^{-1}\right)$. Oral corticosteroid use and more severe airway obstruction at baseline were associated with a higher exacerbation rate. Independent of these variables, asthma patients with frequent exacerbations had a significantly larger annual decline in forced expiratory volume in one second

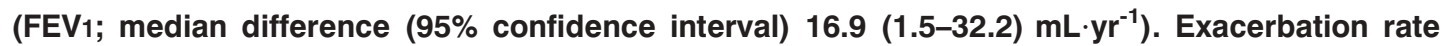
significantly predicted an excess decline in $\mathrm{FEV}_{1}$, such that one severe exacerbation per year was associated with a $30.2 \mathrm{~mL}$ greater annual decline in FEV1.

These data support the hypothesis that exacerbations, indicating intermittent periods of worsening airway inflammation, are associated with excess lung function decline in asthma.

\section{KEYWORDS: Airways remodelling, exacerbations, prognosis, treatment of asthma}

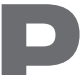
atients with asthma are at risk of developing persistent airflow limitation secondary to structural changes in the airways. Significant obstruction only occurs in a subset of patients and is related to age of onset, disease duration, disease severity, environmental exposures, under-treatment and genetic predisposition [1-4]. It has been proposed that worsening of airway inflammation associated with asthma exacerbations represents periods of enhanced structural airway changes, usually termed airways remodelling. The relationship between exacerbations, which are associated with increased airway inflammation, and accelerated lung function loss in adult asthmatics has not been established. Intuitively, there might be a causal relationship due to the enhanced activation of many inflammation and repair pathways during exacerbations [3], including elevated expression of proteinases such as matrix metalloproteinases [5, 6]. Patients requiring hospitalisation for acute asthma and those requiring courses of oral corticosteroids probably have the most severe (and prolonged) worsening of airway inflammation. Therefore, increased frequency of

For editorial comments see page 411. hospitalisations and severe exacerbations might be associated with an enhanced rate of lung function decline and a greater prevalence of nonreversible airflow limitation. Alternatively, it may be the severity of the underlying chronic inflammation and/or other host factors that are the key determinants of lung function decline, which in this case might be unrelated to hospitalisation and severe exacerbation frequency. However, there are no data on the relationship between exacerbation rate and lung function decline in adults with asthma $[3,7]$.

The present study examined the long-term effect of exacerbations on annual lung function decline in a historical cohort of moderate-to-severe nonsmoking asthmatics. To ensure that the effect of the airway inflammation was unmodified by inhaled corticosteroids (ICS), only lung function data taken before the administration of ICS were included.

\section{METHODS \\ Patients}

The characteristics of the present cohort have been published previously [8]. Briefly, a population of 281 adults with predominantly moderate (forced expiratory volume in one second (FEV1)
AFFILIATIONS

*James Hogg iCapture Centre, St Paul's Hospital, University of British Columbia, Vancouver, BC, Canada. Depts of ${ }^{\#}$ Epidemiology, and

'Pulmonology, University Medical Center Groningen, University of Groningen, Groningen, The Netherlands.

CORRESPONDENCE

T.R. Bai

Respiratory Division

University of British Columbia

Rm 166

St Paul's Hospital

1081 Burrard Street

Vancouver V6Z1Y6

BC

Canada

Fax: 16048068351

E-mail: tbai@mrl.ubc.ca

Received:

December 192006

Accepted after revision:

May 072007

SUPPORT STATEMENT

This work was supported by a Spinoza award to D.S. Postma (Netherlands Organisation for Scientific Research, the Hague, the Netherlands) and by Canadian Institutes of Health Research grant 42537 (Ottowa, ON, Canada).

STATEMENT OF INTEREST

None declared.

European Respiratory Journal Print ISSN 0903-1936 Online ISSN 1399-3003 
$<80 \%$ predicted) or severe (FEV1 $<60 \%$ pred) persistent asthma, based on the Global Initiative for Asthma guidelines [9], was initially evaluated using a standardised protocol between 1962 1975 and closely followed thereafter with spirometry (performed on usual medication, including $\beta$-agonists) at every visit or admission. Patients attended the clinic on a regular basis during follow-up (generally once, twice, or four times per year) and if their asthma condition was deteriorating, unscheduled visits were made. Bronchial responsiveness, serum immunoglobulin $\mathrm{E}$ and detailed pulmonary function tests were reevaluated in 1990. At enrolment, all patients had bronchial hyperresponsiveness to histamine (provocative concentration causing a $20 \%$ fall in FEV1 $\leqslant 32 \mathrm{mg} \cdot \mathrm{mL}^{-1}$, using a modification by de Vries and co-workers of the Tiffeneau method, as described by VONK et al. [8]). All subjects with $>5$ pack-yr smoking history were excluded. Subjects without continuous records for $\geqslant 5 \mathrm{yrs}$ from the age of $25 \mathrm{yrs}$, at which time lung function has maximised [10], were also excluded. Overall, 93 subjects were included in the current study pertaining to the period before ICS treatment was initiated. Treatment was standardised and directed by the same clinician throughout this period and included: allergen avoidance; injected or oral multergan (thiazinamium methyl sulphate, which has anticholinergic and anti-histaminic properties); sympathomimetic agents by inhalation; and intermittent oral corticosteroid courses and/or continuous low-dose $\left(<15 \mathrm{mg} \cdot\right.$ day $\left.^{-1}\right)$ oral corticosteroids. The same water-sealed spirometer (Lode Spirograph D53; Lode Instruments, Groningen, the Netherlands) was used at the initial study and throughout follow-up, and was calibrated daily. Two valid spirometric measures of FEV1 and slow vital capacity were recorded at each visit. The values for the two FEV1 measurements had to be within $3 \%$ to be considered valid and the highest value was used in the analysis. All original spirometric curves were checked. The study was approved by the medical ethics committee of the University Medical Center Groningen (Groningen, the Netherlands) and written informed consent was obtained from all participants.

\section{Severe exacerbations}

Severe exacerbations were defined as hospitalisations for worsening asthma or as a significant and reversible reduction in FEV1. These significant reductions in FEV1 were initially identified on standardised graphical displays of the entire data set for each patient and were detected as a clear, relatively abrupt, decline in FEV1, using a horizontally compressed scale, similar to the concept described by REDDEL et al. [11] for peak expiratory flow records in asthma. If the reductions in FEV1 were $\geqslant 20 \%$ and $\geqslant 500 \mathrm{~mL}$ from the mean FEV1 value over the 2.5 yrs on each flank of the reduction (excluding exacerbation and admission FEV1 measurements), it was defined as an exacerbation. Review of visit dates showed that exacerbations based on FEV1 reductions were unscheduled office visits. A maximum of one exacerbation per 3-month period was counted.

\section{Statistical analyses}

The 93 patients were divided into two groups, based on the median exacerbation rate $\left(0.10 \cdot \mathrm{yr}^{-1}\right)$. Subjects with an exacerbation rate above the median were defined as having frequent exacerbations, whereas subjects with an exacerbation rate below the median were defined as having infrequent exacerbations. Baseline variables between these groups were compared using the Chi-squared test for categorical variables, and unpaired t-tests or Mann-Whitney U-tests as appropriate for continuous variables. To analyse the effect of hospitalisations and severe exacerbations on the annual decline of FEV1, a linear mixed effects (LME) model was used [4]. Lung function data obtained during hospitalisations/exacerbations were not used in the analyses. In the LME model, an indicator variable for group was included to estimate the difference in FEV1 decline between groups. Height, sex, the first available FEV1 after age 25 yrs (centred at $2.7 \mathrm{~L}$ ), the interaction of these with time, and oral corticosteroid use as a time-varying variable, were included in the model [12].

\section{RESULTS}

The characteristics of the study population are presented in table 1. The median duration of follow-up was $11 \mathrm{yrs}$ in the ICS-untreated period. During this time 186 severe exacerbations based on hospitalisation or change in FEV1, were identified: 33 hospitalisations and 153 exacerbations based on change in FEV1. A group of 56 (60.2\%) subjects experienced at least one severe exacerbation, with a median rate of $0.10 \cdot \mathrm{yr}^{-1}$. An illustrative graph of FEV1 measures over $35 \mathrm{yrs}$ in one patient is shown in figure 1 .

The mean \pm SD values of recorded FEV1 values were $62.0 \pm 22 \%$ pred $(2.35 \pm 1.04 \mathrm{~L})$ during hospitalisations, $39.7 \pm 14.4 \%$ pred $(1.37 \pm 0.58 \mathrm{~L})$ during exacerbations and $71.4 \pm 19.5 \%$ pred $(2.47 \pm 0.88 \mathrm{~L})$ at all other measurement points. The characteristics

TABLE 1 Baseline characteristics of subjects with asthma

$\begin{array}{lc}\text { Subjects } \mathbf{n} & 93 \\ \text { Female } & 53(57.0) \\ \text { Age at start of analyses yrs } & 27(25-36) \\ \text { Height } \mathbf{~ c m} & 171 \pm 9 \\ \text { FEV } \mathbf{~ L} & 2.69 \pm 0.91 \\ \text { FEV } 1 \text { \% pred } & 72 \pm 19 \\ \text { Reversibility \% pred } & 24 \pm 12 \\ \text { VC L } & 4.32 \pm 1.11 \\ \text { FEV } \mathbf{1} / \mathbf{V C} & 62 \pm 14 \\ \text { PC } \mathbf{2 0}^{\#} \leqslant \mathbf{8} \mathbf{m g} \cdot \mathbf{m L}^{-\mathbf{1}} & 66(71.0) \\ \text { Blood eosinophils } \geqslant \mathbf{2 2 0} \times \mathbf{1 0}^{\mathbf{9}} \cdot \mathbf{L}^{-\mathbf{1}} & 69(75.0) \\ \text { HDM-positive } & 74(79.6) \\ \text { Atopic } & 84(90.3) \\ \text { Age at symptom onset yrs } & 4(2-17) \\ \text { Untreated period } \mathbf{y r s} & 17(11-24) \\ \text { Duration of analyses } \mathbf{y r s} & 11(8-16) \\ \text { OCS duration yrs } & 0.0(0.0-0.2)\end{array}$

Data are presented as $n(\%)$, median (interquartile range) or mean $\pm S D$, unless otherwise stated. FEV1: forced expiratory volume in one second; \% pred: \% predicted; VC: vital capacity; PC20: provocative concentration causing a $20 \%$ fall in FEV1; HDM: house dust mite; OCS: oral corticosteroid. "\#: PC20 $\leqslant 8 \mathrm{mg} \cdot \mathrm{mL}^{-1}$ histamine is a measure of severity of bronchial hyperresponsiveness since all subjects had a $\mathrm{PC}_{20} \leqslant 32 \mathrm{mg} \cdot \mathrm{mL}^{-1}$ histamine and were thus diagnosed as being hyperresponsive; $"$ : time with asthma prior to first attendance at asthma centre. 


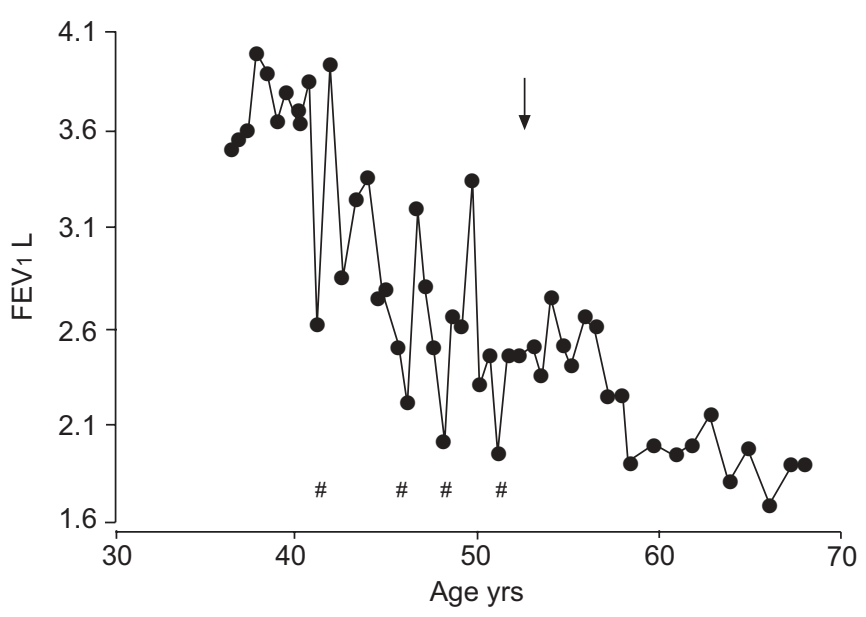

FIGURE 1. Forced expiratory volume in one second (FEV1) records over a $35-y r$ period in a subject with four exacerbations. Low-dose continuous oral corticosteroids ( $3-13 \mathrm{mg} \cdot$ day $^{-1}$ prednisolone) were in use for the first $20 \mathrm{yrs}$ of follow-up, prior to the introduction of inhaled corticosteroids (arrow). ${ }^{*}$ : time-point of exacerbation

of the subjects subdivided by median exacerbation rate are shown in table 2.

Subjects with frequent exacerbations had more severe airway obstruction at baseline and were house dust mite-negative more often, compared with subjects with infrequent exacerbations.
Severity of airways hyperresponsiveness, bronchodilator reversibility, blood eosinophil count and age of symptomatic onset of asthma were not significantly different between the groups. Although subjects with frequent exacerbations were more often females and nonatopic compared with subjects with infrequent exacerbations, these differences were not statistically significant. The proportion of subjects with adult onset symptoms was also not different between the two groups (table 2).

A total of 1,939 FEV1 measurements were analysed from the 93 patients during the ICS-untreated period, excluding lung function measurements during exacerbations or hospital admissions. Decline in mean FEV1 (95\% confidence interval) was $14.6(1.9-27.3) \mathrm{mL} \cdot \mathrm{yr}^{-1}$ in those with infrequent exacerbations and $31.5(18.2-44.8) \mathrm{mL} \cdot \mathrm{yr}^{-1}$ in asthmatics with frequent exacerbations, the difference between the groups being 16.9 (1.5-32.2) $\mathrm{mL} \cdot \mathrm{yr}^{-1}$ ( $\mathrm{p}=0.03$; fig. 2). After $11 \mathrm{yrs}, \mathrm{FEV} 1$ was $64.3 \pm 18.9 \%$ pred $(2.08 \pm 0.72 \mathrm{~L})$ in the group with frequent exacerbations, compared with $77.2 \pm 19.1 \%$ pred $(2.69 \pm 0.93 \mathrm{~L})$ in those with infrequent exacerbations $(\mathrm{p}=0.002)$. A higher exacerbation rate (expressed as a continuous variable) was associated with an excess decline in FEV1, such that one severe exacerbation per year was associated with a $30.2(3.7-56.7) \mathrm{mL}$ greater annual decline in FEV1. Additional adjustment for body mass index did not alter the relationship between exacerbations and FEV1 decline, nor did exclusion of the two subjects who had irreversible airway obstruction at baseline. Inclusion of house dust mite positivity in the LME model slightly decreased the difference in FEV1 decline between

TABLE 2 Characteristics of subjects subdivided by median exacerbation rate

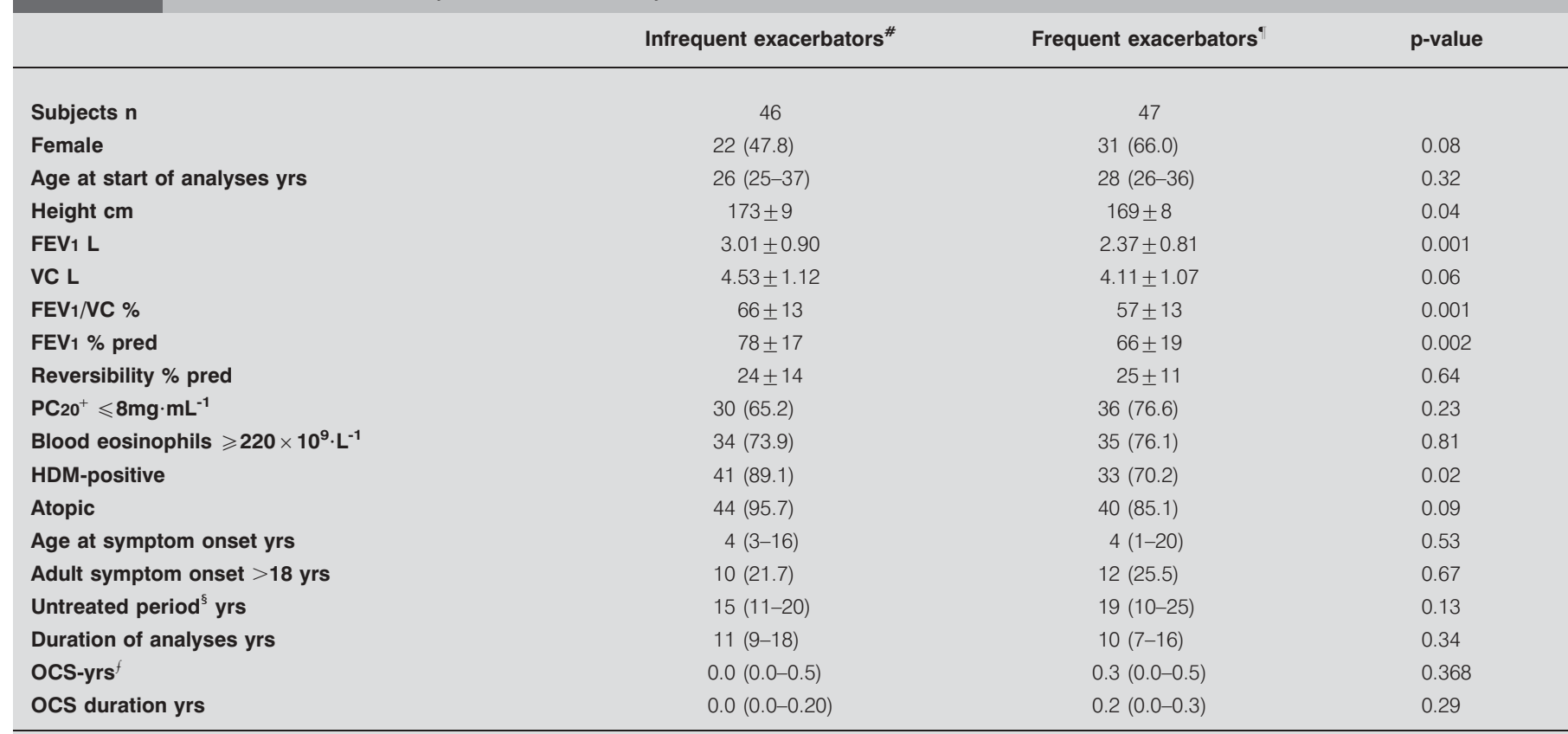

Data are presented as $n(\%)$, median (interquartile range) or mean \pm SD, unless otherwise stated. FEV1: forced expiratory volume in one second; VC: vital capacity; \% pred: $\%$ predicted; PC20: provocative concentration causing a 20\% fall in FEV1; HDM: house dust mite; OCS: oral corticosteroid. ${ }^{\#}:<0.10$ exacerbations $\cdot \mathrm{yr}^{-1}$; ${ }^{\top}:>0.10$ exacerbations $\cdot \mathrm{yr}^{-1}$; $^{+}: \mathrm{PC}_{20} \leqslant 8 \mathrm{mg} \cdot \mathrm{mL}^{-1}$ histamine is a measure of severity of bronchial hyperresponsiveness since all subjects had a PC20 $\leqslant 32 \mathrm{mg} \cdot \mathrm{mL}^{-1}$ histamine and were thus diagnosed as being hyperresponsive; ${ }^{\text {s: }}$ : time with asthma prior to first attendance at asthma centre; $f^{f}: 1$ OCS-yr use of 5 mg.day ${ }^{-1}$ prednisolone for 1 yr, 2 OCSyrs is $5 \mathrm{mg} \cdot \mathrm{day}^{-1}$ for $2 \mathrm{yrs}$ or $10 \mathrm{mg} \cdot$ day $^{-1}$ for $1 \mathrm{yr}$, etc. 
subjects with frequent and infrequent exacerbations (from 16.9 to $\left.13.8 \mathrm{~mL} \cdot \mathrm{yr}^{-1}\right)$.

Given that even a low level of smoking could conceivably influence exacerbation rates, the analyses were repeated and restricted to subjects with 0 pack-yrs. This did not change the estimated FEV1 decline in both the infrequent and frequent exacerbator groups (low: $6.5 \mathrm{~mL} \cdot \mathrm{yr}^{-1}$; high: $31.5 \mathrm{~mL} \cdot \mathrm{yr}^{-1}$ ). These results suggest there is no confounding or modification of the original associations by smoking history.

\section{DISCUSSION}

The present study is the first to demonstrate that asthmatics with frequent exacerbations experience excess decline in FEV1 and more severe airway obstruction after 11 yrs follow-up. The current findings show that exacerbations represent periods of accelerated structural changes in the airways, otherwise known as airways remodelling. The results provide additional rationale for the notion that the prevention of exacerbations should be a primary end-point in trials of asthma therapy.

Since the effects of only severe exacerbations on lung function decline were examined, and mild exacerbations were not included, the results of the present study may actually be an underestimation of the true overall effects. Moreover, the overall effects of exacerbations might have been underestimated because some patients were on continuous low-dose oral corticosteroids. Additionally, the fact that all patients were studied during the relative plateau phase of their FEV1, between the ages of 25 and $40 \mathrm{yrs}$, thus missing the lung function decline phase that is usually seen at an elderly age, might also have led to underestimation of the overall effect of exacerbations on lung function decline. Since FEV1 measures during exacerbations were excluded from the analysis of rate of decline in FEV1, the current findings cannot simply be a reflection of the increased airflow variability of poor asthma control or of greater intrinsic severity in those with frequent exacerbations. The decline in FEV1 in infrequent exacerbators was not significantly different

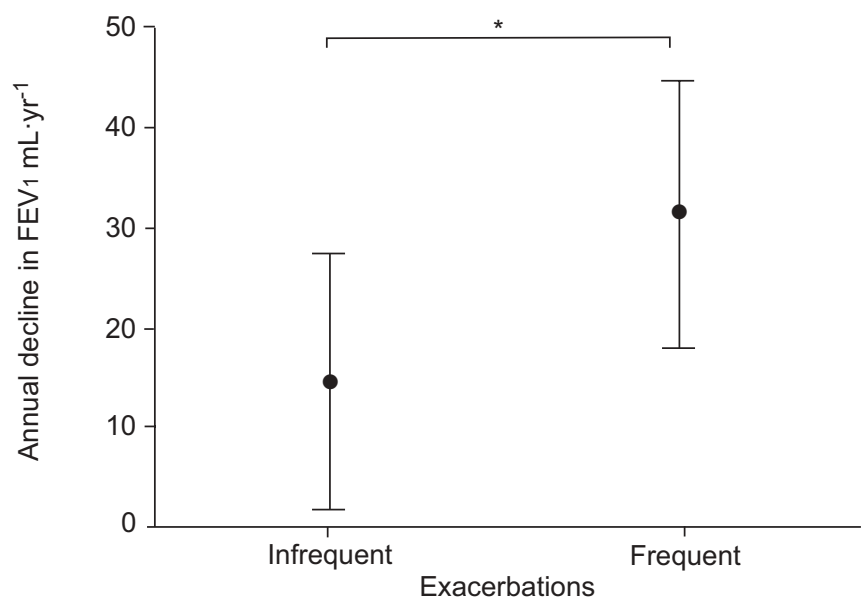

FIGURE 2. Estimated annual decline in forced expiratory volume in one second $\left(F E V_{1}\right)$ in patients with infrequent or frequent asthma exacerbations. The analysis was adjusted for sex, height, the first available FEV 1 after age 25 yrs and the use of oral corticosteroids. The error bars represent $95 \%$ confidence intervals. *: $p<0.05$ between the groups from the general Dutch population after age 30 yrs (i.e. $18.7 \mathrm{~mL} \cdot \mathrm{yr}^{-1}$ ) [13]. Notwithstanding this, the earlier age of initiation of analysis in the present asthma cohort $(\geqslant 25.0 \mathrm{yrs})$ and relatively short period of follow-up, compared with the observations in the general Dutch population, may have underestimated lung function decline, with accelerated decline in FEV1 being primarily detected in mid-life and older asthmatic subjects [2]. The present study has also shown that females more often tend to be frequent exacerbators; this is supported by previous findings in studies of asthmatics, in which females required hospitalisation more frequently [14].

Testing the hypothesis of the present study required evaluation during long-term treatment without ICS, and hence the need to perform a retrospective cohort study. A prospective cohort study in patients not receiving ICS is unlikely to occur for ethical reasons. Although the results of the present study do not necessarily reflect outcomes under current best practice guidelines, in reality many patients still do not have access to, or use, ICS on a regular basis and are therefore at risk of accelerated decline in lung function. Ideally, all subjects receiving continuous oral corticosteroids would have been excluded from the current study, but this was not feasible due to sample size constraints. Likewise, adjustments for additional possible confounders affecting decline, such as effects of occupational exposures and comorbidities, could not be made.

Unlike chronic obstructive pulmonary disease (COPD), asthma is not a disease generally acknowledged as being associated with either significant irreversible airway obstruction or an accelerated decline in FEV1. However, treatment-resistant impairment in airflow rates is frequently apparent on diagnosis of asthma, and usually inferred as secondary to structural change in the pre-symptomatic phase [3]. Multiple factors have been associated with excess decline in lung function in adult patients with asthma, including more severe airway hyperresponsiveness and baseline airway obstruction [1], older age [2, 15], adult onset of asthma [16] and, within adults, onset at an older age [17]. Prior studies of adult asthmatic populations provided insufficient data to distinguish whether it is chronic severity, exacerbation frequency or associated factors, such as smoking, that dictate the progression of lung function decline [18]. Although an accelerated longitudinal decline in lung function may reflect ongoing structural changes, a labile component secondary to airway plugging, airway wall oedema and inflammatory cell infiltrates in those with relative corticosteroid resistance cannot easily be excluded [19].

DONALDSON et al. [20] reported an $8 \mathrm{~mL} \cdot \mathrm{yr}^{-1}$ greater decline in FEV1 over a 4-yr period in patients with moderate or severe COPD who had frequent exacerbations, compared with those who had less frequent exacerbations. The differences in rates of decline are less than the effect of exacerbations found in the current study, with an overall decline of $36 \mathrm{~mL} \cdot \mathrm{yr}^{-1}$ paralleling the effect detected in individuals with frequent exacerbations $\left(31.5 \mathrm{~mL} \cdot \mathrm{yr}^{-1}\right)$. In the current study, the association was not due to the modest smoking history reported by some subjects.

The present analyses, based on a period when only symptomatic treatment with or without maintenance oral steroids was 
utilised, may have yielded a different result if periods of regular ICS use had been included. For the duration of the study, it was not possible to attribute exacerbations to specific triggers, such as infections or allergens, although triggers may vary in their effect on airway function. During regular ICS treatment, a greater proportion of exacerbations may represent infection-induced neutrophilic inflammation unresponsive to ICS [21], and may influence airway structure in a different manner to exacerbations during a period of long-term poor asthma control without regular ICS, with a greater frequency of eosinophilic inflammatory events. Conversely, however, neutrophilic inflammation has been proposed to be more deleterious to airway structure [22]. Although regular oral corticosteroid use during follow-up was more common in the group with frequent exacerbations (results not shown), a significantly greater decline was still seen after adjusting for this use. Regular oral corticosteroid use is expected to suppress eosinophilic airway influx, but conceivably could have increased neutrophil influx and thus airway damage; alternately regular oral corticosteroid use could have lead to a delay in the recognition of exacerbations and thus worsened airway structural change.

In conclusion, the current data support the hypothesis that intermittent periods of worsening airway inflammation during asthma exacerbations, when there is elevated expression of many molecular pathways that may enhance airway remodelling, lead to excess decline in lung function in asthma.

\section{REFERENCES}

1 Peat JK, Woolcock AJ, Cullen K. Rate of decline of lung function in subjects with asthma. Eur J Respir Dis 1987; 70: 171-179.

2 Lange P, Parner J, Vestbo J, Schnohr P, Jensen G. A 15-year follow-up study of ventilatory function in adults with asthma. N Engl J Med 1998; 339: 1194-1200.

3 Bai TR, Knight DA. Structural changes in the airways in asthma: observations and consequences. Clin Sci (Lond) 2005; 108: 463-477.

4 Jongepier H, Boezen HM, Dijkstra A, et al. Polymorphisms of the ADAM33 gene are associated with accelerated lung function decline in asthma. Clin Exp Allergy 2004; 34: 757-760.

5 Oshita Y, Koga T, Kamimura T, Matsuo K, Rikimaru T, Aizawa $\mathrm{H}$. Increased circulating $92 \mathrm{kDa}$ matrix metalloproteinase (MMP-9) activity in exacerbations of asthma. Thorax 2003; 58: 757-760.

6 Shute JK, Parmar J, Holgate ST, Howarth PH. Urinary glycosaminoglycan levels are increased in acute severe asthma-a role for eosinophil-derived gelatinase B? Int Arch Allergy Immunol 1997; 113: 366-367.

7 Pauwels RA. Similarities and differences in asthma and chronic obstructive pulmonary disease exacerbations. Proc Am Thorac Soc 2004; 1: 73-76.
8 Vonk JM, Jongepier H, Panhuysen CI, Schouten JP Bleecker ER, Postma DS. Risk factors associated with the presence of irreversible airflow limitation and reduced transfer coefficient in patients with asthma after 26 years of follow up. Thorax 2003; 58: 322-327.

9 Global Initiative for Asthma (GINA). National Heart, Lung and Blood Institute/World Health Organization Workshop Report: Global Strategy for Asthma Management and Prevention issued January, 1995. National Institutes of Health publication 02-3659. www.ginasthma.com Date last updated: 2005.

10 Apostol GG, Jacobs DR Jr, Tsai AW, et al. Early life factors contribute to the decrease in lung function between ages 18 and 40: the Coronary Artery Risk Development in Young Adults study. Am J Respir Crit Care Med 2002; 166: 166-172.

11 Reddel HK, Vincent SD, Civitico J. The need for standardisation of peak flow charts. Thorax 2005; 60: 164-167.

12 Dijkstra A, Vonk JM, Jongepier H, et al. Lung function decline in asthma: association with inhaled corticosteroids, smoking and sex. Thorax 2006; 61: 105-110.

13 Van Diemen CC, Postma DS, Vonk JM, Bruinenberg M, Schouten JP, Boezen HM. A disintegrin and metalloprotease 33 polymorphisms and lung function decline in the general population. Am J Respir Crit Care Med 2005; 172: 329-333.

14 Prescott E, Lange P, Vestbo J. Effect of gender on hospital admissions for asthma and prevalence of self-reported asthma: a prospective study based on a sample of the general population. Copenhagen City Heart Study Group. Thorax 1997; 52: 287-289.

15 Bumbacea D, Campbell D, Nguyen L, et al. Parameters associated with persistent airflow obstruction in chronic severe asthma. Eur Respir J 2004; 24: 122-128.

16 ten Brinke A, Zwinderman AH, Sterk PJ, Rabe KF, Bel EH. Factors associated with persistent airflow limitation in severe asthma. Am J Respir Crit Care Med 2001; 164: 744-748.

17 Panizza JA, James AL, Ryan G, de Klerk N, Finucane KE. Mortality and airflow obstruction in asthma: a 17-year follow-up study. Intern Med J 2006; 36: 773-780.

18 Ulrik CS, Backer V. Nonreversible airflow obstruction in life-long nonsmokers with moderate to severe asthma. Eur Respir J 1999; 14: 892-896.

19 ten Brinke A, Zwinderman AH, Sterk PJ, Rabe KF, Bel EH. "Refractory" eosinophilic airway inflammation in severe asthma: effect of parenteral corticosteroids. Am J Respir Crit Care Med 2004; 170: 601-605.

20 Donaldson GC, Seemungal TA, Bhowmik A, Wedzicha JA. Relationship between exacerbation frequency and lung function decline in chronic obstructive pulmonary disease. Thorax 2002; 57: 847-852.

21 Reddel H, Ware S, Marks G, Salome C, Jenkins C, Woolcock A. Differences between asthma exacerbations and poor asthma control. Lancet 1999; 353: 364-369.

22 Lindén A, Laan M, Anderson GP. Neutrophils, interleukin17A and lung disease. Eur Respir J 2005; 25: 159-172. 